\title{
Statistical comparison of foliage spectral and biochemical measurements on an example of Norway spruce stands in the Ore Mountains, Czech Republic
}

\author{
Markéta Potůčkováa ${ }^{\text {, Lucie Červenáa }}{ }^{\text {, Lucie Kupkováa }}{ }^{\text {, Zuzana Lhotákováb }}{ }^{\mathrm{b}}$ \\ and Jana Albrechtováb \\ Charles University in Prague, Faculty of Science \\ ${ }^{a}$ Department of Applied Geoinformatics and Cartography \\ ${ }^{\mathrm{b}}$ Department of Experimental Plant Biology \\ \{marketa.potuckova, jana.albrechtova\}@natur.cuni.cz, \\ \{LucieCervena, zuza.lhotak\}@seznam.cz, Lucie.kupkova@gmail.com
}

\begin{abstract}
The physiological status of vegetation and changes can be monitored by means of biochemical analysis of collected samples as well as by means of spectroscopic measurements either on the leaf level, using field (or laboratory) spectroradiometers or on the canopy level, applying hyperspectral airborne or spaceborne image data. The present study focuses on the statistical comparison and ascertainment of relations between three datasets collected from selected Norway spruce forest stands in the Ore Mountains, Czech Republic. The data sets comprised i) biochemically retrieved photosynthetic pigments (chlorophylls, carotenoids) and water content of 495 samples collected from 55 trees from three different vertical levels of a tree crown and the first three needle age classes, ii) the spectral reflectance of the same shoot samples measured with an ASD Field Spec 4 Wide-Res spectroradiometer equipped with a plant contact probe, iii) an airborne hyperspecral image acquired with an Apex sensor. The datasets cover two areas (western and central) in the Ore Mountains that were affected differently by acid deposits in the 1970's and 1980's. A one-way analysis of variance (ANOVA), Tukey's honest significance test, hot spot analysis and linear regression were applied either on the original measurements (the content of leaf compounds and reflectance spectra) or derived values, i.e. selected spectral indices. The results revealed a generally low correlation between the photosynthetic pigments, water content and spectral measurement. The results of the ANOVA showed significant differences between model areas only in the case of the leaf compound dataset. Differences between the stands on various levels of significance existed in all three datasets and are discussed. The study also proved that the vertical gradient of the biochemical and biophysical parameters in a tree crown play a role when the optical properties of the forest stands are modelled. It is possible to conclude that the differences in the physiological conditions of stands observed in high extent in 1998 still were slightly detectable in 2013, though the physiological conditions levelled up. From the point of view of optical properties, the differences between the areas are not significant on laboratory or image reflectance spectra.
\end{abstract}

Keywords: Laboratory spectroscopy, hyperspectral imagery, Ore Mountains, Norway spruce, Chlorophyll, Carotenoids, RWC.

Geoinformatics FCE CTU 15(1), 2016, doi:10.14311/gi.15.1.6 


\section{Introduction}

Laboratory and image-based spectral measurements have been used in numerous biological, ecological and environmental studies to evaluate the physiological status of the vegetation [4], [16]. Variations in plant condition are indicated e.g. by changes in the content of specific leaf compounds such as photosynthetic pigments (chlorophylls, carotenoids) and water that can be determined by biochemical analyses of the collected leaf samples. The optical properties of the leaves follow these changes (e.g. [6], [25]). It has been documented that a worsening of the physiological status of vegetation can be detected either from the biochemical or biophysical parameters, because the metabolic changes occur much earlier than macroscopic changes such as needle yellowing or needle loss. Similarly, those initial damage phases of leaves can be detected from their spectra prior to observation from macroscopic indicators. For example, Campbell et al. [5] detected the initial stages of foliage damage in Norway spruce (Picea abies L. Karst.) using ASAS hyperspectral airborne data and vegetation indices derived from red edge. The relation between the optical properties of vegetation and its biochemical or biophysical parameters can be described using empirical models (e.g. [7], [15]) or radiative transfer models (e.g. [8], [9], [14], [20]).

The Norway spruce forests in the Ore Mountains (Western Bohemia) were strongly affected by acid deposits (mainly $\mathrm{SO}_{2}$ ) causing heavy damage between 1970 and 2000, especially in the central part of the mountain range. The principal sources of $\mathrm{SO}_{2}$ pollution were industry and coal burning power plants located in the south-eastern foothills of the Ore Mountains. Due to the prevailing eastward direction of the wind, the disturbance of the western part of the mountains was considerably less than that in the central and eastern parts [1]. The study conducted by Campbell et al. [5] in 1998 evaluated the level of forest damage in two areas selected in the central and western areas of the mountains using, among other things such as macroscopic damage indicators, image spectroscopy and biochemically determined content of leaf photosynthetic pigments and water in the collected needle samples. The tree damage followed the west-east gradient in air $\mathrm{SO}_{2}$ pollution with heavier damage of the Norway spruce stands in the central Ore Mountains in comparison with the stands in the western Ore Mountains. In 2012, a follow up project aiming at evaluating the physiological status of the Norway spruce stands at the same two areas and several identical study stands started. This study again combined biochemical determination of leaf compounds and spectroscopic measurements of the optical properties of canopy on both the needle (laboratory spectroscopic measurements) and the crown (hyperspectral images) levels. The presented study is a part of this project.

The main objectives of the presented study were to find out if i) the differences in the physiological status of the Norway spruce stands still exist between the selected model areas (located in the western and central Ore Mountains); ii) the same differences can be detected from biochemical analysis, laboratory and airborne image spectroscopic measurements; iii) the recognised differences will change depending on the 'scale', i.e. when the areas, stands, position in the crown and the age of the shoots are considered.

\section{Material}

The study areas were situated in the Ore Mountains in the areas that were either heavily damaged in 1998 (the central part in the neighbourhood of the Kovářská village) or in the 
initial damage stage without severe visual symptoms (the western part in the neighbourhood of the town of Přebuz) due to acid deposits in the 1970's and 1980's. Within the homogeneous Norway spruce mature forest (50 years and older), five even-aged representative trees were selected at each of eleven study stands (five for the Kovářská and six for the Přebuz areas, see Figure 1). During the field campaign, 22 - 25 August 2013, the samples from three vertical crown levels (the sunlit productive upper and lower parts and the shaded basal part of the tree crown) and the first three needle age classes were collected. Laboratory spectral measurements using an ASD Field Spec 4 Wide-Res spectroradiometer and assessment of photosynthetic pigments and water content were carried out on these 495 samples. The airborne image hyperspectral data were acquired with the APEX sensor on 6 September 2013; a supporting field calibration and validation campaign was conducted on the same date.

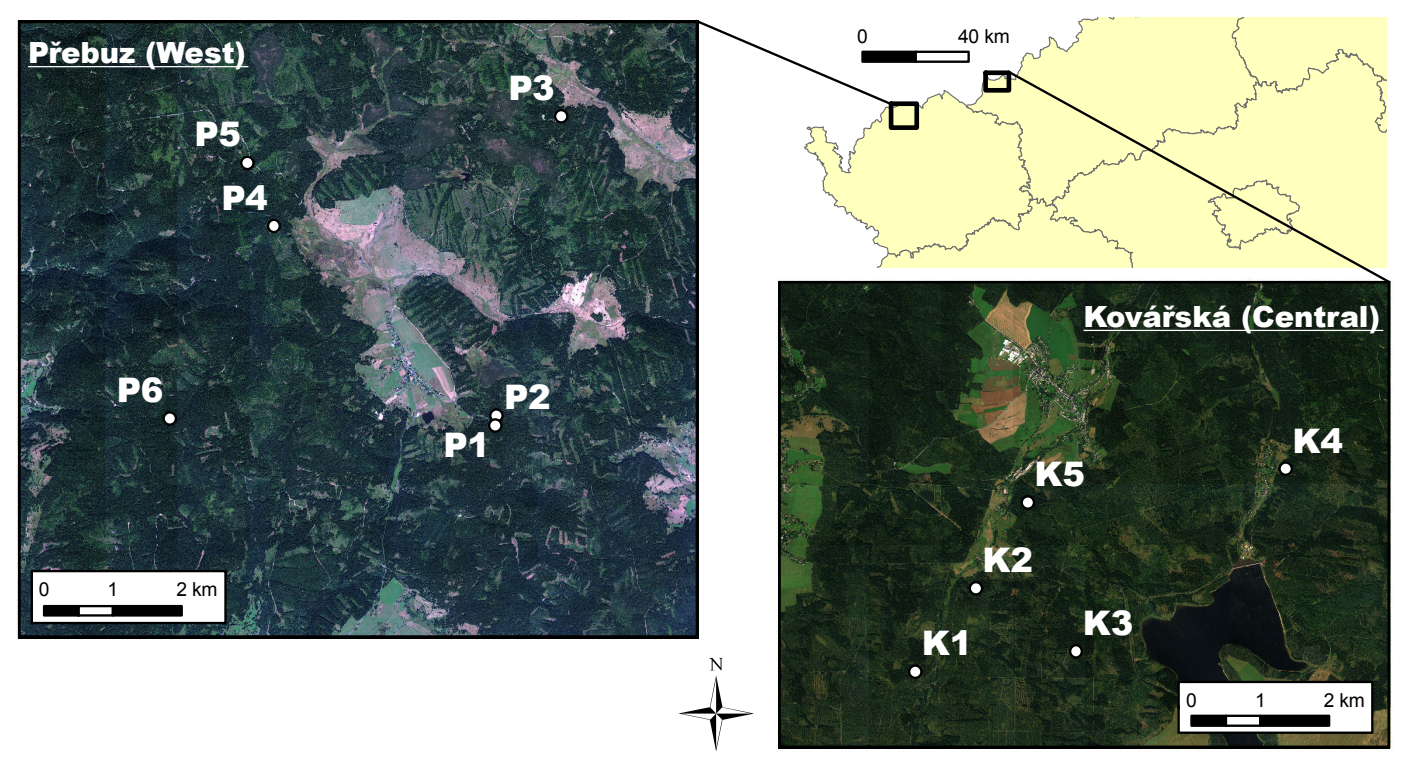

Figure 1: The location of the study areas Kovářská and Přebuz with Norway spruce stands. Each stand was represented by five selected trees.

\section{Biochemical and biophysical parameters}

Needle samples collected in the field were cooled and transported to the laboratory where they were stored and frozen to $-20^{\circ} \mathrm{C}$ until processing. The extraction of photosynthetic pigments (chlorophyll a and b and total carotenoids) was performed according to [23] and [27]. The relative water content (RWC) corresponded to the percentage of water in the fresh needles. Table 1 summarises the content of analysed leaf compounds related to the areas (A) and position of the sample in the tree crown (B). In the following text, the results connected to the content of the biochemical and biophysical parameters will be referred to as BioC/P.

\section{Laboratory spectral measurements}

The laboratory spectral measurements were performed with an ASD Field Spec 4 WideRes spectroradiometer equipped with a plant contact probe $(\mathrm{CP})$. The spectroradiometer collects radiance in the spectral interval from $350 \mathrm{~nm}$ to $2,500 \mathrm{~nm}$ using three detectors 
Table 1: Descriptive statistics of the leaf photosynthetic pigments and relative water content in needles of Norway spruce. A: for the study areas of Kovářská (central) and Přebuz (western). B: for the position in the crown. st.d. - standard deviation, d.m. - dry mass.

\begin{tabular}{|c|c|c|c|c|}
\hline A: Area & \multicolumn{2}{|c|}{ Přebuz (western) } & \multicolumn{2}{c|}{ Kovářská (central) } \\
\hline Descriptive statistics & mean & st.d. & mean & st.d. \\
\hline Total chlorophyll (mg/g d.m.) & 2.97 & 0.66 & 3.19 & 0.67 \\
\hline Total carotenoids (mg/g d.m.) & 0.40 & 0.08 & 0.42 & 0.08 \\
\hline Relative water content (\%) & 56.27 & 3.11 & 56.91 & 3.22 \\
\hline
\end{tabular}

\begin{tabular}{|c|c|c|c|c|c|c|c|c|}
\hline B: Position in the crown & \multicolumn{2}{|c|}{ Shaded basal } & \multicolumn{2}{c|}{ Productive lower } & \multicolumn{2}{c|}{ Productive upper } & \multicolumn{2}{c|}{ All data } \\
\hline Descriptive statistics & mean & st.d. & mean & st.d. & mean & st.d. & mean & st.d. \\
\hline Total chlorophyll (mg/g d.m.) & 3.44 & 0.62 & 3.10 & 0.66 & 2.76 & 0.55 & 3.09 & 0.66 \\
\hline Total carotenoids (mg/g d.m.) & 0.44 & 0.07 & 0.41 & 0.08 & 0.37 & 0.07 & 0.41 & 0.08 \\
\hline Relative water content (\%) & 57.91 & 2.76 & 56.26 & 3.13 & 55.46 & 3.12 & 56.53 & 3.17 \\
\hline
\end{tabular}

(VNIR: $350-1,000 \mathrm{~nm}$, SWIR1: 1,000 - 1,800 nm and SWIR2: 1,800 - 2,500 nm). The original spectral resolution is $3 \mathrm{~nm}$ in VNIR and $10 \mathrm{~nm}$ in SWIR bands and sampling interval of $1.4 \mathrm{~nm}$. The output data are resampled to $1 \mathrm{~nm}$ interval using cubic spline interpolation [3], [2]. Due to the noise in the collected measurements, the applied spectral interval was reduced to wavelengths between 400 and 2,400 $\mathrm{nm}$ in the presented study.

A layer of Norway spruce shoots of the same age class arranged in the same direction and with minimal gaps were placed on a black surface ( $98 \%$ absorption) to minimize background spectral noise. In order to improve the spectral-to-noise ratio, 50 measurements at one position of the $\mathrm{CP}$ were averaged. Moreover, each sample was measured at five positions of the CP and their median was used further as the final ASD CP observation of one sample. The relative reflectance of the Norway spruce samples was calculated from the recorded spectral radiance values by normalizing them with the measured radiance of a $99 \%$ reflective spectralon according to the formula:

$$
R_{\text {sample }}=\frac{D N_{\text {sample }}}{D N_{W R}}
$$

where $R_{\text {sample }}$ is the calculated relative reflectance, $D N_{\text {sample }}$ and $D N_{W R}$ are the recorded digital numbers of the sample and the spectralon (so-called 'white reference'). The needles for biochemical analysis were sampled from the same branch as were the shoots for spectral measurements. For the purpose of comparison with the APEX hyperspectral image data, the ASD CP measurements were resampled to the bands with the central wavelengths and full width at half maximum value (FWHM) corresponding approximately to the APEX data (based on metadata FWM ranges from 3 to $13 \mathrm{~nm}$, dependent on the wavelength).

\section{Hyperspectral image data}

Airborne hyperspectral images were acquired with the APEX (Airborne Prism Experiment) sensor working in the spectral rage from $400 \mathrm{~nm}$ to $2,500 \mathrm{~nm}$. The images contained 286 spectral bands with an average bandwidth of $7 \mathrm{~nm}$. The ground resolution was 2 metres. The image acquisition, pre-processing, radiometric calibration, geometric and atmospheric corrections were performed by the Belgian company VITO (more details can be found in [21], 
[24]). The position of each tree was determined by GNSS. As the average crown diameter was about $5 \mathrm{~m}$, the four nearest pixels to the measured tree location were selected. The spectra corresponding to these four pixels were manually checked and after removing possible outliers due to e.g. shadows, a mean of spectra was calculated and used for further processing as the spectrum representing the given tree (see Figure 2).
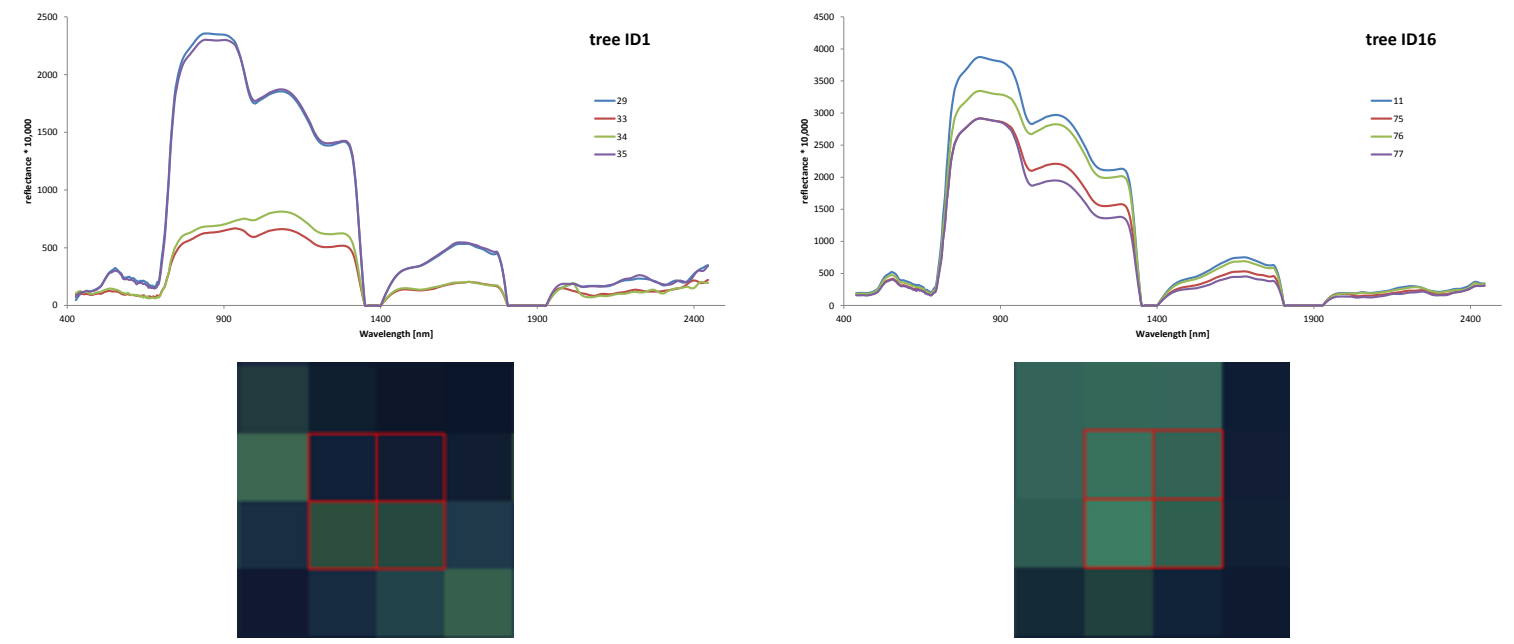

Figure 2: Averaging the APEX spectra. The tree crown is represented by four neighbouring pixels. In the event that the spectral reflectance of some pixels significantly differed from the others and from the expected 'vegetation' spectrum, it was not included in the calculation of the mean (left - spectra 33 and 34 will be excluded due to shadows; right - the mean of all spectra will be calculated).

\section{Methods for spectra comparison}

To evaluate the differences in the measured values of $\mathrm{BioC} / \mathrm{P}$ and optical properties of the needles between various factors (area, stand, needle age class and position in the crown), a two-step procedure was adopted. First, one-way analysis of variance (ANOVA) was used to test whether any differences between the groups of the examined factor exist. The tested null hypothesis was that the means of all the groups were equal. When the null hypothesis was rejected at the confidence level of $95 \%(\alpha=0.05)$, the alternative hypothesis was valid, i.e. at least one group was significantly different. To find out which group means were the most distinct from the others, the multiple comparison Tukey's honest significance test was performed afterwards. Both statistical analyses were carried out in the $\mathrm{R}$ software package using the aov and TukeyHSD functions. Interactions between the factors (and therefore the multiple factor ANOVA) were not applied in order to keep the interpretation of the results simple and to be able to find the differences between the specific groups of the given factor.

A hot spot analysis based on the evaluation of the spatial association of a variable within a specified distance of a single point [10] was run in ArcGIS software in order to validate the above-mentioned methods on the tree level and to visualize the space distribution of the sought differences of the evaluated parameters, e.g. the contents of photosynthetic pigments and water. This method identifies statistically significant hot spots (high values) and cold spots (low values) within the context of the neighbouring features. A feature with a high/low 
value is considered to be a statistically significant hot/cold spot just in the event that it is surrounded by other features with high/low values as well.

Further, spectral indices, which showed the highest correlation with the chlorophyll, carotenoids and water contents in Norway spruce needles in our previous studies (e.g. [7]) were calculated in order to compare the results of $\mathrm{BioC} / \mathrm{P}$ and spectral measurements when evaluating the differences between groups on all possible levels of detail. $R_{x}$ refers to spectral reflectance on the wavelength $x \mathrm{~nm}$ in the formulas 2 to 6 .

Ratio of Transformed Chlorophyll Absorption Ratio Index and Optimized Soil Adjusted Vegetation Index TCARI/OSAVI [12]; higher values of this index indicate less chlorophyll content:

$$
\text { TCARI/OSAVI }=\frac{3 \times\left[\left(R_{700}-R_{670}\right)-0.2 \times\left(R_{700}-R_{550}\right) \times\left(\frac{R_{700}}{R_{670}}\right)\right]}{\frac{1.16 \times\left(R_{800}-R_{670}\right)}{R_{800}+R_{670}+0.16}}
$$

Modified Red Edge Normalized Difference Vegetation Index $\mathrm{mND}_{705}$ or MRENDVI in ENVI $5.3[25]$ corrects for leaf specular reflection:

$$
M R E N D V I=\frac{R_{750}-R_{705}}{R_{750}+R_{705}-2 \times R_{445}}
$$

Carotenoids' concentration index CRI700 [11]:

$$
C R I^{r} 00=\frac{1}{R_{515}}-\frac{1}{R_{700}}
$$

Water Index WI [22]:

$$
W I=\frac{R_{900}}{R_{970}}
$$

Moisture stress index MSI (formula 6) indicates the water stress of the plants, i.e. the higher values of the index indicate a lower water content [13].

$$
M S I=\frac{R_{1600}}{R_{820}}
$$

The empirical relation between the BioC/P parameters and the indices derived from laboratory and image spectra was estimated using linear regression and its strength was expressed by the coefficient of determination $\mathrm{R}^{2}$.

\section{Results}

Several tests based on one-way analysis of variance (ANOVA) were carried out for BioC/P, laboratory and image spectroscopic data in order to indicate whether significant differences in the measured values are dependent on the location (area and stand). Moreover, the BioC/P and ASD CP data allowed comparison between positions in the tree crown and needle age classes.

In the first test, the differences in the measured laboratory spectra between the two areas were evaluated. The relative spectral reflectance values collected for all the samples on the 
two study areas (western Kovářská - 225 samples and central Přebuz - 270 samples) on each wavelength in the interval from 400 to $2,400 \mathrm{~nm}$ were used as inputs to ANOVA. The results showed that there were no significant differences where the areas were considered $(\mathrm{p}>0.05)$. On the other hand, the spectra differed significantly $(\mathrm{p} \ll 0.05)$ if the stands are used as the factor in ANOVA with the only exception of the narrow interval around 1,900 nm (the water absorption band). The same test carried out on the image spectra revealed no significant dependence on the area or on the stand with the exception of the wavelengths around 660 nm, i.e. the chlorophyll absorption band (Figure 3).
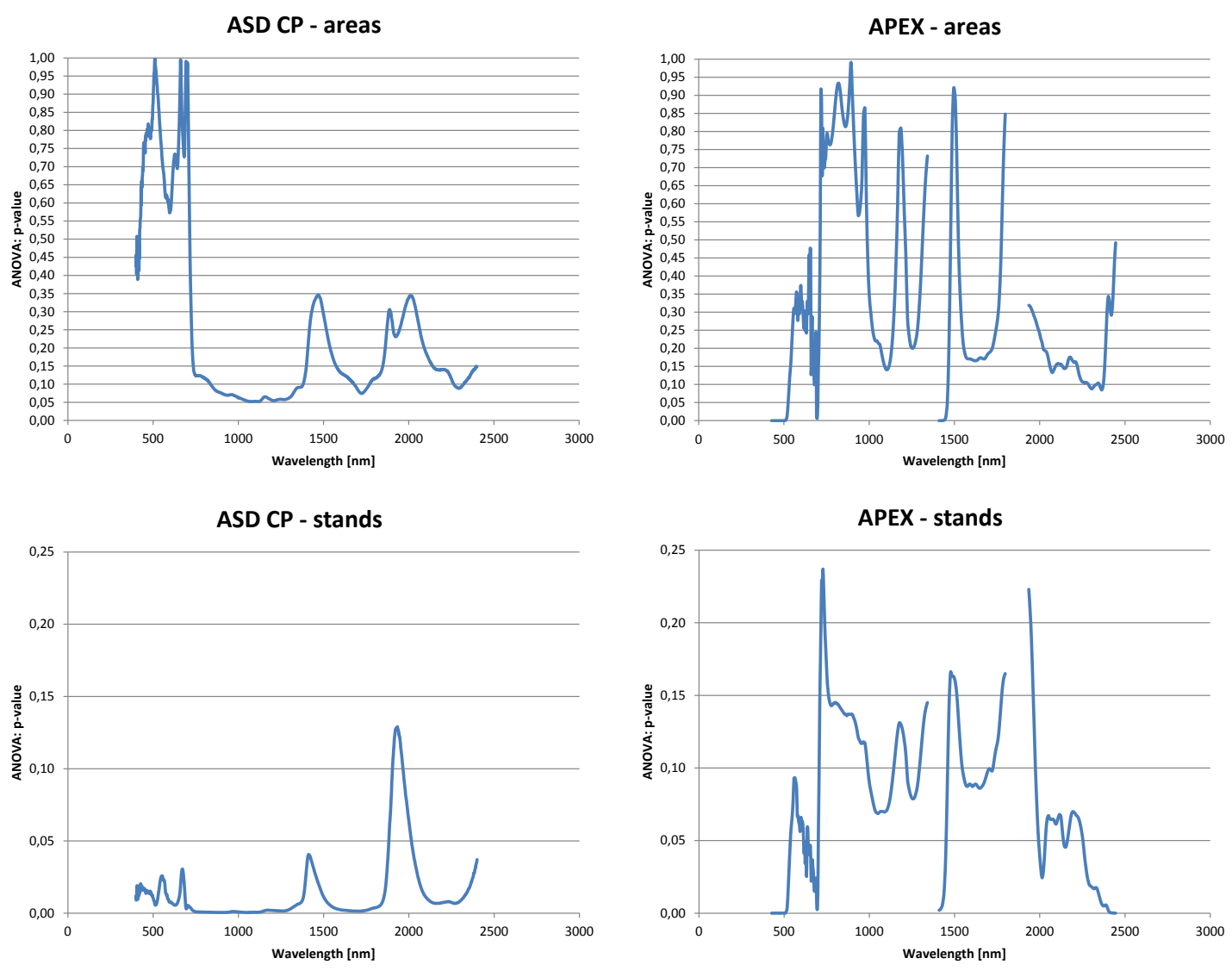

Figure 3: p-values of ANOVA $(\alpha=0.05)$ showed the significance of differences in the collected Norway spruce laboratory (ASD CP) and image spectra (Apex) dependent on the single factors of area and stand. $\mathrm{p}>0.05$ indicates that the areas and stands do not differ significantly.

In the second test, the TCARI/OSAVI, CRI700 and WI indices were derived from both laboratory and airborne image spectra. The ANOVA was carried out again in order to find out if there are differences in the content of leaf pigments (chlorophyll and carotenoids) and water dependent on the following single factors (where relevant) - area, stand, position in the crown and age of the shoots. The BioC/P measurements of the Norway spruce samples were also included in order to be able to perform a comparison of all three methods. In the case of BioC/P and ASD CP measurements, 495 samples were used and in the case of the APEX data, it was 55 samples corresponding to single trees. In addition, a reduction of observations was performed for BioC/P and ASD CP measurements by averaging the leaf 
compounds and spectral indices' values for each tree. Thus, the number of measurements also decreased to 55 and they were comparable to the image data. Table $2 \mathrm{~A}$ shows that the BioC/P measurements of pigments and water content revealed dependence on all studied factors. Regarding pigments, ASD CP derived indices are in correspondence with the BioC/P measurements with the exception of the area factor. On the other hand, the results of ANOVA based on the TCARI/OSAVI and CRI700 indices corresponded to the results carried out on spectral measurements (ASD CP: 495 samples, Apex: 55 samples; also compare Figure 3). Stronger dependence of relative water content was observed only on the detailed structure levels of trees, i.e. when the position in the crown or age of the shoots were considered as factors for the analysis. As expected, reducing the number of observations by averaging brought a higher similarity between all three types of measurements and it caused smaller differences between observations (Table 2B).

Table 2: Results of single factor ANOVA for BioC/P measurements and indices derived from laboratory and image spectral measurements on Norway spruce - A: 495 samples, B: 55 samples. Location parameters on different levels of detail were used as factors in the analysis. Significance codes: $0 \leq p \leq 0.001$ : $\star \star \star$ (very significant), $0.001<p \leq 0.01$ : $\star \star$, $0.01<p \leq 0.05: \star, 0.05<p \leq 0.1: \circ$ and $0.1<p \leq 1$ : n.s. (not significant).

\begin{tabular}{|c|c|c|c|c|c|c|}
\hline \multirow{2}{*}{ A: 495 samples } & \multicolumn{2}{|c|}{ Chlorophyll } & \multicolumn{2}{c|}{ Carotenoids } & \multicolumn{2}{c|}{ Relative water content } \\
\cline { 2 - 6 } & BioC/P & $\begin{array}{c}\text { ASD CP: } \\
\text { TCARI/OSAVI }\end{array}$ & BioC/P & $\begin{array}{c}\text { ASD CP: } \\
\text { CRI700 }\end{array}$ & BioC/P & ASD CP: WI \\
\hline Area & $\star \star \star$ & n.s. & $\star \star$ & n.s. & $\star$ & n.s. \\
\hline Stand & $\star \star \star$ & $\star \star \star$ & $\star \star \star$ & $\star \star \star$ & $\circ$ & n.s. \\
\hline Position in the crown & $\star \star \star$ & $\star$ & $\star \star \star$ & $\star \star$ & $\star \star \star$ & n.s. \\
\hline Age of the shoots & $\star \star \star$ & $\star \star \star$ & $\star \star \star$ & $\star \star \star$ & $\star \star \star$ & $\star \star \star$ \\
\hline
\end{tabular}

\begin{tabular}{|c|c|c|c|c|c|c|c|c|c|}
\hline \multirow{3}{*}{ B: 55 samples } & \multicolumn{3}{|c|}{ Chlorophyll } & \multicolumn{3}{|c|}{ Carotenoids } & \multicolumn{3}{|c|}{ Relative water content } \\
\hline & \multirow{2}{*}{$\mathrm{BioC} / \mathrm{P}$} & \multicolumn{2}{|c|}{ TCARI/OSAVI } & \multirow{2}{*}{$\mathrm{BioC} / \mathrm{P}$} & \multicolumn{2}{|c|}{ CRI700 } & \multirow{2}{*}{$\mathrm{BioC} / \mathrm{P}$} & \multicolumn{2}{|c|}{$\mathrm{Wi}$} \\
\hline & & ASD CP & Apex & & ASD CP & Apex & & ASD CP & Apex \\
\hline Area & $\star$ & n.s. & $\star$ & o & n.s. & n.s. & o & n.s. & n.s. \\
\hline Stand & $\star$ & o & $\star$ & n.s. & $\star$ & $\star$ & n.s. & n.s. & n.s. \\
\hline
\end{tabular}

The Tukey's HSD test performed on the BioC/P and ASD CP data revealed that there were stands significantly different from others and it also confirmed results published earlier about differences of the pigment and water contents in the tree vertical profile [26] and between younger and older tree shoots (e.g. [19]). The outcomes of the Tukey's HSD test are summarised in Table 3 .

The spatial distribution of the differences among stands with respect to the contents of the leaf pigments and water was also calculated using Hot Spot Analysis (Getis-Ord Gi*) in the ArcGIS software and further visualised (see Appendix p. 83). The spectra resampled to the Apex resolution were applied for calculation of the indices in the case of the ASD $\mathrm{CP}$ data. In the case of $\mathrm{BioC} / \mathrm{P}$ measurements, the hot spot analysis detected significantly higher chlorophyll and water contents at stands K5 and K2, respectively, and lower carotenoid content at stand P4, which confirmed the results of Tukey's HSD test. The results of both analyses were also in agreement in the case of the ASD CP data (compare Table 3B and Table 4). 
Table 3: Results of Tukey's HSD test showing the extremes in factors used in ANOVA. A: summary of extreme differences in three factors. The cases in which the ANOVA did not reveal significant results are marked in red (compare Tab. 2.A). B: ID of stands with significantly highest/lowest values of the leaf pigment and water content. C: same as B but with regard to the position in the crown and age of the shoots.

\begin{tabular}{|c|c|c|c|c|c|c|}
\hline \multirow{2}{*}{ A: Max. differences } & \multicolumn{2}{|c|}{ Chlorophyll } & \multicolumn{2}{c|}{ Carotenoids } & \multicolumn{2}{c|}{ Relative water content } \\
\cline { 2 - 7 } & BioC/P & $\begin{array}{c}\text { ASD CP: } \\
\text { TCARI/OSAVI }\end{array}$ & BioC/P & $\begin{array}{c}\text { ASD CP: } \\
\text { CRI700 }\end{array}$ & BioC/P & ASD CP: WI \\
\hline Stand & K5, P2 & P4, K2, K5 & K5, P4 & K3, K2 & K2, K4 & P4, P1 \\
\hline Position in the crown & H-D & H-D, S-H & H-D & H-D & H-D, S-D & S-D \\
\hline Age of the shoots & $1-2,1-3$ & $1-2,1-3$ & $1-3$ & $1-3$ & $1-2,1-3$ & $1-3$ \\
\hline
\end{tabular}

\begin{tabular}{|c|c|c|c|c|c|c|}
\hline \multirow{2}{*}{ B: Stand } & \multicolumn{2}{|c|}{ Chlorophyll } & \multicolumn{2}{c|}{ Carotenoids } & \multicolumn{2}{c|}{ Relative water content } \\
\cline { 2 - 7 } & BioC/P & $\begin{array}{c}\text { ASD CP: } \\
\text { TCARI/OSAVI }\end{array}$ & BioC/P & $\begin{array}{c}\text { ASD CP: } \\
\text { CRI700 }\end{array}$ & BioC/P & ASD CP: WI \\
\hline Lowest values & P2, P4 & K5 & P4 & K2 & -- & -- \\
\hline Highest values & K5 & P4, K2 & K5 & K3 & K2, K4, K5 & P4, P1, K2 \\
\hline
\end{tabular}

\begin{tabular}{|c|c|c|c|c|}
\hline \multirow{2}{*}{$\begin{array}{c}\text { C: Position in the crown } \\
\text { Age of the shoots }\end{array}$} & \multicolumn{2}{|c|}{ Maximum } & \multicolumn{2}{c|}{ Minimum } \\
\cline { 2 - 5 } & Shoots & Position & Shoots & Position \\
\hline Chlorophyll & 3 & Shaded basal & 1 & Productive upper \\
\hline Carotenoids & 3 & Shaded basal & 1 & Productive upper \\
\hline Relative water content & 1 & Shaded basal & 3 & Productive upper \\
\hline
\end{tabular}

Table 3B and Table 4 also showed that both performed tests did not mark the same stands as significantly different when the various measurement methods (BioC/P, ASD CP and Apex) were compared. These discrepancies could be explained mainly by the fact that, though correlated, each of the methods worked with samples of a different hierarchical scale (level of detail). The 'cross' position of stands $\mathrm{P} 4$ and $\mathrm{K} 5$ in the BioC/P and ASD CP columns is correct, as the low value of chlorophyll content is expressed with a high value of the presented TCARI/OSAVI index and vice versa. A weak relation between the BioC/P, ASD CP and Apex measurements is demonstrated in Figure 4 showing the correlation between the leaf pigment and water content and vegetation indices derived from the ASD CP and Apex spectral reflectance values. No higher correlation was achieved by using other spectral indices sensitive to chlorophyll or water contents, e.g. the coefficient of determination $\mathrm{R}^{2}$ of the linear regres-

Table 4: Stand IDs with significantly highest/lowest values of leaf pigment and water content according to hot spot analysis.

\begin{tabular}{|c|c|c|c|c|c|c|c|c|c|}
\hline \multirow{3}{*}{ Stand } & \multicolumn{3}{|c|}{ Chlorophyll } & \multicolumn{3}{|c|}{ Carotenoids } & \multicolumn{3}{|c|}{ Relative water content } \\
\hline & \multirow{2}{*}{$\mathrm{BioC} / \mathrm{P}$} & \multicolumn{2}{|c|}{ TCARI/OSAVI } & \multirow{2}{*}{$\mathrm{BioC} / \mathrm{P}$} & \multicolumn{2}{|c|}{ CRI700 } & \multirow{2}{*}{$\mathrm{BioC} / \mathrm{P}$} & \multicolumn{2}{|c|}{ WI } \\
\hline & & ASD CP & Apex & & ASD CP & Apex & & ASD CP & Apex \\
\hline $\begin{array}{c}\text { Lowest } \\
\text { values }\end{array}$ & $\mathrm{P} 4, \mathrm{P} 2$ & K5 & $\mathrm{P} 1, \mathrm{P} 5$ & $\mathrm{P} 4$ & K2 & P5 & -- & K5 & -- \\
\hline $\begin{array}{c}\text { Highest } \\
\text { values }\end{array}$ & K5 & $\mathrm{P} 4, \mathrm{~K} 2$ & K1 & -- & K3 & P3 & K2 & K2 & P6 \\
\hline
\end{tabular}


sion between ASD CP and Apex MRENDVI and MSI equalled 0.039 and 0.002, respectively.
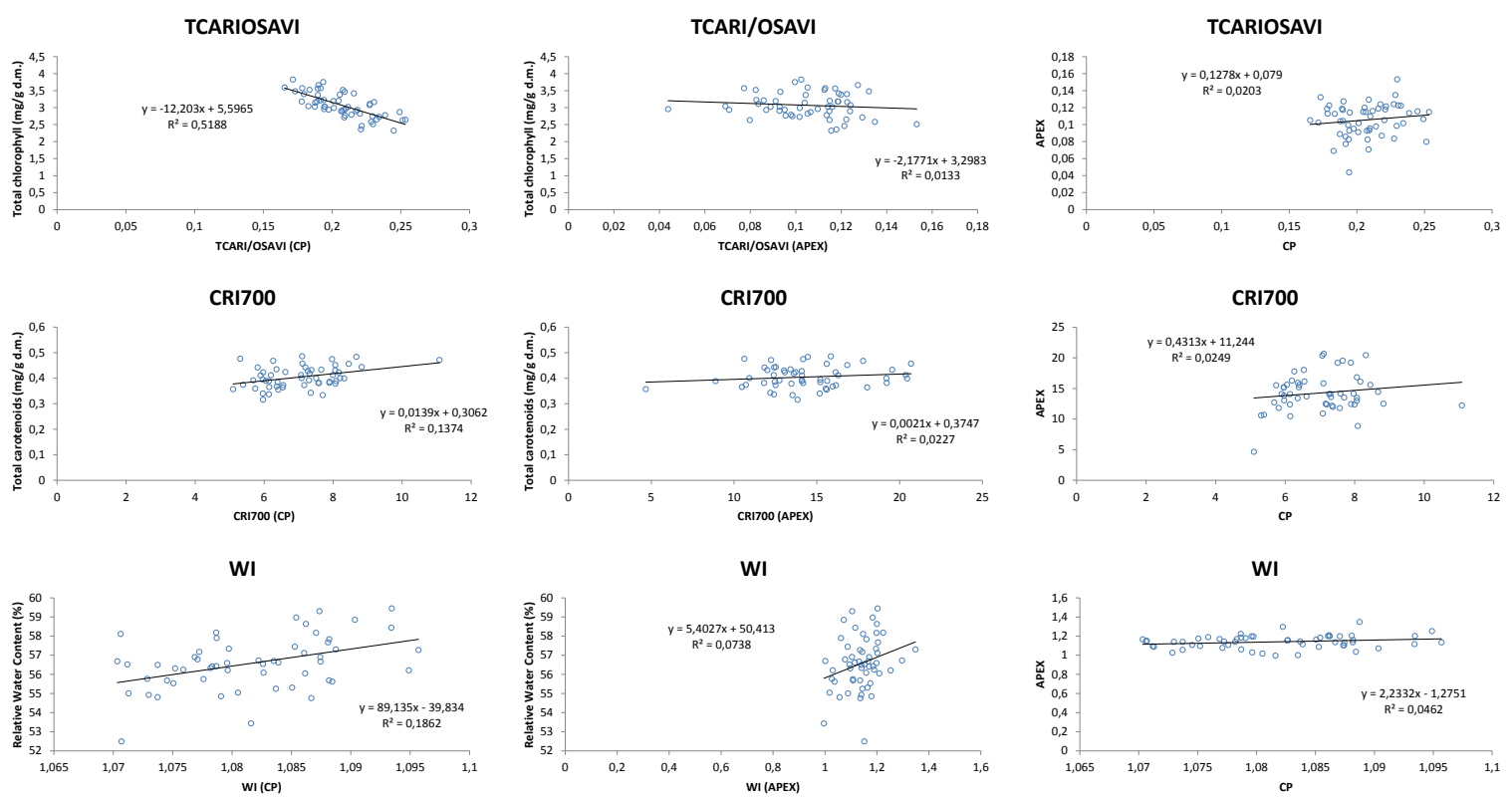

Figure 4: Relation between biochemically derived leaf compounds and indices calculated from laboratory (ASD CP) and image (APEX) spectral reflectance values expressed by means of linear regression and the coefficient of determination $\mathrm{R}^{2}$.

The resampling of ASD CP data to the Apex spectral resolution did not improve the correlation between the indices and BioC/P. Nevertheless, Figure 5 demonstrates well a higher homogeneity of laboratory derived indices in comparison with indices derived from airborne images. A systematic shift between corresponding indices can also be observed.

\section{Discussion}

From Table 1 it is obvious that the mean values of the $\mathrm{BioC} / \mathrm{P}$ parameters were slightly lower in the Přebuz area. The comparison based on the BioC/P parameters revealed significant differences for all factors tested by one-way ANOVA (Table 2A). The question remains why significant differences were also observed for the area factor. Mišurec et al. [21] came to the conclusion that the significant differences in pigment and water needle contents did not exist in this case what can be explained by the different subset of shoots included in the tests: the values of BioC/P for only one of the tree vertical crown levels were used in that study [21]. Considering the vertical position of needles within the tree crown as a very significant factor mediated by irradiance gradient and influencing pigment and water contents as well as spectral indices (Table 2), it was not surprising that by selecting only one vertical position, the results could shift. Table $2 \mathrm{~A}$ also shows that there was a good agreement between the results using photosynthetic pigments and TCARI/OSAVI and CRI700 indices as variables in ANOVA on the stand, position in the crown and the needle level and the observed differences are significant in all these cases. A low significance is obtained as soon as the measurements are averaged on the position and stand levels in the cases of relative water content and WI. The results of the Tukey's HSD test are in correspondence with results found in literature - the 

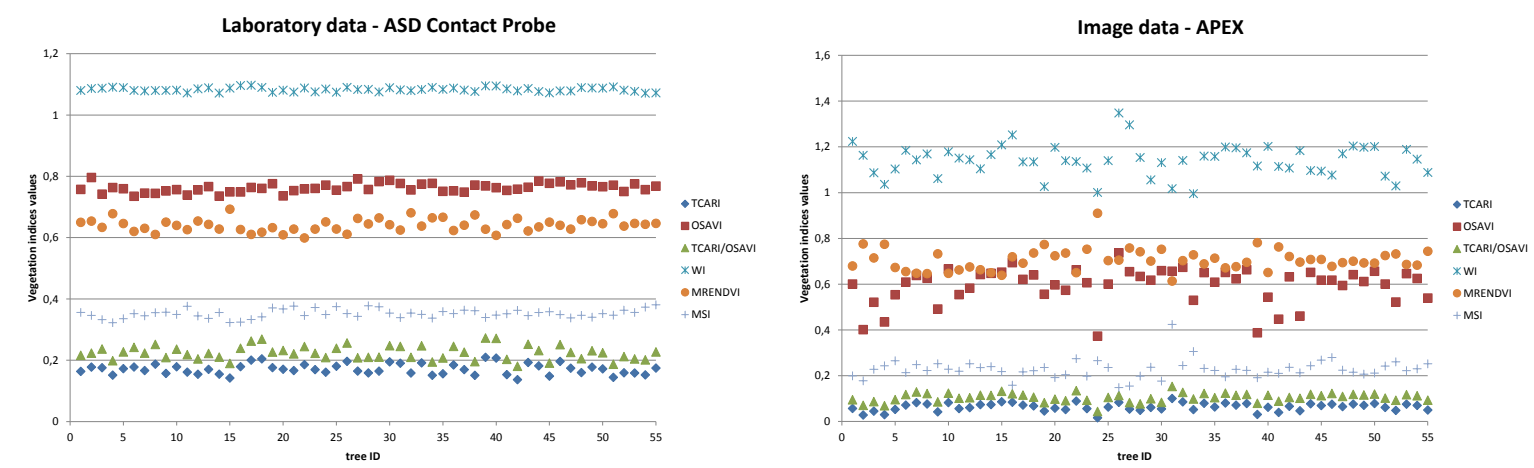

Figure 5: Spectral indices derived from APEX data and ASD CP spectra resampled to Apex spectral resolution. Each stand consists of five trees: stand P1: trees ID 1-5, .., P6: 26-30, K1: $31-35, \ldots, \mathrm{K} 5:$ 51-55. CRI700 is not included due to its higher absolute values in comparison with other indices.

content of photosynthetic pigments (expressed on needle dry mass) increases from the upper to lower parts of the tree crown and with the age of the shoots, while the water content shows an opposite trend [7], [26]. Averaging the BioC/P and ASD CP observations per tree brought better agreement with the optical hyperspectral data. However, it diminished the variability and the number of observations in the dataset and, thus, lowered the significance levels of differences between the observed factors. For future studies, the weighing of observation dependent on the position in the crown shall be considered, as the lower crown parts do not have to have the same influence on the radiation collected by the airborne sensor, especially in the case of the denser forest stands.

The performed hot-spot analysis clearly showed the spatial distribution of stands with significantly different (low or high) values of the observed BioC/P parameters or indices. This was its main advantage in the comparison with the Tukey's HSD test. Both types of results can be used in further analysis concerning the relation to other environmental parameters such as soil composition and properties or macroscopic evaluation of physiological status of forest stands.

The correlation between the BioC/P parameters and indices calculated from the ACD $\mathrm{CP}$ and APEX spectra proved to be very low in comparison with other studies on conifers (e.g. [17], [18]) which can be explained by the generally low variability in the observed parameters. As expected, due to the origin of the samples, the relatively highest correlation was obtained for the BioC/P and ASD CP measurements. Empirical models based on the same dataset using more spectral indices and partial least square regression are further elaborated in [7].

\section{Conclusion}

The presented study focused on revealing connections between the foliar chemistry compounds, laboratory and airborne image spectroscopic measurements. While the first two can be used for an evaluation of the physiological condition of vegetation on different hierarchical levels within a stand, the airborne hyperspectral data provide large scale evaluation on a canopy level. It was shown that similar results could be obtained when the detailed data 
were averaged on a tree level (and optionally resampled to the spectral resolution of the image data). The results support the findings that the vertical gradient of the BioC/P parameters in the canopy play a role when the optical properties of forest stands are modelled. Regarding the physiological status of Norway spruce in the model areas, based on the BioC/P parameters, it is possible to conclude that the differences in the physiological conditions of stands observed in high extent in 1998 [5] still existed in 2013, though they were rather mild considering the absolute values of the derived compounds. From the point of view of optical properties, the differences between the areas are not significant on laboratory or image reflectance spectra.

\section{Acknowledgements}

The study was supported by the Ministry of Education, Youth and Sports of the Czech Republic under Grant No LH 12097 (PI J. Albrechtová) and NPUI LO1417.

\section{References}

[1] Jonas Ardö et al. "Satellite Based Estimations of Coniferous Forest Cover Changes: Krusne Hory, Czech Republic". In: Ambio 26.3 (1997), pp. 158-166.

[2] ASD Inc. Analytical Spectral Devices. 2013. URL: http://www . asdi.com/productsand-services (visited on 06/03/2016).

[3] ASD Inc. Analytical spectral devices. Ed. by David C Hatchell. Technical Guide 3rd. Ed. 1999. URL: http: //www . geo-informatie.nl/courses/grs60312/fieldwork/ New $\% 20$ Folder $\% 20 \% 282 \% 29 /$ Fieldspec\%20fieldguide $\% 20 \mathrm{TG}$ _Rev4_web.pdf (visited on $06 / 03 / 2016)$.

[4] Richard J. Aspinall, W. Andrew Marcus, and Joseph W. Boardman. "Considerations in collecting, processing, and analysing high spatial resolution hyperspectral data for environmental investigations". In: Journal of Geographical Systems 4.1 (2002), pp. 1529. DOI: $10.1007 / \mathrm{s} 101090100071$.

[5] P. K. Entcheva Campbell et al. "Detection of initial damage in Norway spruce canopies using hyperspectral airborne data". In: International Journal of Remote Sensing 25.24 (2004), pp. 5557-5584. DOI: 10.1080/01431160410001726058.

[6] Gregory A Carter and Alan K Knapp. "Leaf optical properties in higher plants: linking spectral characteristics to stress and chlorophyll concentration". In: American Journal of Botany 88.4 (2001), pp. 677-684. DOI: 10.2307/2657068.

[7] Lucie Červená et al. "Models for estimating leaf pigments and relative water content in three vertical canopy levels of norway spruce based on laboratory spectroscopy". In: EARSeL 34th Symposium Proceedings. Ed. by B. Zagajewski, M. Kycko, and R. Reuter. EARSeL and University of Warsaw, 16-20 June 2014. DOI: 10.12760/03-2014-11. URL: http : //www . earsel .org/symposia/2014-symposium-Warsaw/pdf_proceedings / EARSeL-Symposium-2014_6_1_cervena.pdf (visited on 06/03/2016).

[8] Roshanak Darvishzadeh et al. "Mapping grassland leaf area index with airborne hyperspectral imagery: A comparison study of statistical approaches and inversion of radiative transfer models". In: ISPRS Journal of Photogrammetry and Remote Sensing 66.6 (2011), pp. 894-906. DOI: 10.1016/j.isprsjprs.2011.09.013. 
[9] Jean-Baptiste Feret et al. "PROSPECT-4 and 5: Advances in the leaf optical properties model separating photosynthetic pigments". In: Remote Sensing of Environment 112.6 (2008), pp. 3030-3043. DOI: 10.1016/j.rse.2008.02.012.

[10] Arthur Getis and J Keith Ord. "The analysis of spatial association by use of distance statistics". In: Geographical analysis 24.3 (1992), pp. 189-206. DOI: 10.1111/j.15384632.1992.tb00261.x.

[11] Anatoly A Gitelson et al. "Assessing carotenoid content in plant leaves with reflectance spectroscopy". In: Photochemistry and Photobiology 75.3 (2002), pp. 272-281. DOI: 10. 1562/0031-8655(2002)0750272accipl2.0.co2.

[12] Driss Haboudane et al. "Integrated narrow-band vegetation indices for prediction of crop chlorophyll content for application to precision agriculture". In: Remote sensing of environment 81.2 (2002), pp. 416-426. DOI: 10.1016/s0034-4257(02) 00018-4.

[13] E Raymond Hunt and Barrett N Rock. "Detection of changes in leaf water content using near-and middle-infrared reflectances". In: Remote sensing of environment 30.1 (1989), pp. 43-54. DOI: 10.1016/0034-4257 (89) 90046-1.

[14] Stéphane Jacquemoud et al. "PROSPECT+ SAIL models: A review of use for vegetation characterization". In: Remote Sensing of Environment 113 (2009), S56-S66. DOI: 10. 1016/j.rse.2008.01.026.

[15] Raymond F Kokaly and Roger N Clark. "Spectroscopic determination of leaf biochemistry using band-depth analysis of absorption features and stepwise multiple linear regression". In: Remote sensing of environment 67.3 (1999), pp. 267-287. DOI: 10.1016/ s0034-4257 (98) 00084-4.

[16] Raymond F Kokaly et al. "Characterizing canopy biochemistry from imaging spectroscopy and its application to ecosystem studies". In: Remote Sensing of Environment 113 (2009), S78-S91. DOI: 10.1016/j.rse.2008.10.018.

[17] Lucie Kupková et al. "Chlorophyll determination in silver birch and scots pine foliage from heavy metal polluted regions using spectral reflectance data". In: EARSeL eProceedings. Vol. 11. 1. 2012, pp. 64-73. URL: http://eproceedings.org/static/ vol11_1/11_1_kupkova1.pdf (visited on 06/03/2016).

[18] Zuzana Lhotáková et al. "Detection of multiple stresses in Scots pine growing at postmining sites using visible to near-infrared spectroscopy". In: Environmental Science: Processes 6 Impacts 15.11 (2013), pp. 2004-2015. DOI: 10.1039/c3em00388d.

[19] Zuzana Lhotáková et al. "Does the azimuth orientation of Norway spruce (Picea abies/L. /Karst.) branches within sunlit crown part influence the heterogeneity of biochemical, structural and spectral characteristics of needles?" In: Environmental and experimental botany 59.3 (2007), pp. 283-292. DOI: 10.1016/j.envexpbot.2006.02.003.

[20] Z Malenovský et al. "Applicability of the PROSPECT model for Norway spruce needles". In: International Journal of Remote Sensing 27.24 (2006), pp. 5315-5340. DOI: $10.1080 / 01431160600762990$.

[21] Jan Mišurec et al. "Detection of Spatio-Temporal Changes of Norway Spruce Forest Stands in Ore Mountains Using Landsat Time Series and Airborne Hyperspectral Imagery". In: Remote Sensing 8.2 (2016), p. 92. DOI: 10.3390/rs8020092. 
[22] J Peñuelas et al. "Estimation of plant water concentration by the reflectance water index WI (R900/R970)". In: International Journal of Remote Sensing 18.13 (1997), pp. 2869-2875. DOI: 10.1080/014311697217396.

[23] RJ Porra, WA Thompson, and PE Kriedemann. "Determination of accurate extinction coefficients and simultaneous equations for assaying chlorophylls a and b extracted with four different solvents: verification of the concentration of chlorophyll standards by atomic absorption spectroscopy". In: Biochimica et Biophysica Acta (BBA)-Bioenergetics 975.3 (1989), pp. 384-394. DOI: 0.1016/s0005-2728(89)80347-0.

[24] Michael E Schaepman et al. "Advanced radiometry measurements and Earth science applications with the Airborne Prism Experiment (APEX)". In: Remote Sensing of Environment 158 (2015), pp. 207-219. DOI: 10.1016/j.rse.2014.11.014.

[25] Daniel A Sims and John A Gamon. "Relationships between leaf pigment content and spectral reflectance across a wide range of species, leaf structures and developmental stages". In: Remote sensing of environment 81.2 (2002), pp. 337-354. DOI: 10.1016/ s0034-4257(02)00010-x.

[26] Quan Wang and Pingheng Li. "Canopy vertical heterogeneity plays a critical role in reflectance simulation". In: Agricultural and forest meteorology 169 (2013), pp. 111121. DOI: $10.1016 / \mathrm{j}$.agrformet.2012.10.004.

[27] Alan R Wellburn. "The spectral determination of chlorophylls a and b, as well as total carotenoids, using various solvents with spectrophotometers of different resolution". In: Journal of plant physiology 144.3 (1994), pp. 307-313. DOI: 10.1016/s0176-1617(11) 81192-2. 
Appendix: The spatial distribution of the differences among stands with respect to the content of the leaf pigments and water calculated using Hot Spot Analysis (Getis-Ord Gi*) in the ArcGIS software.
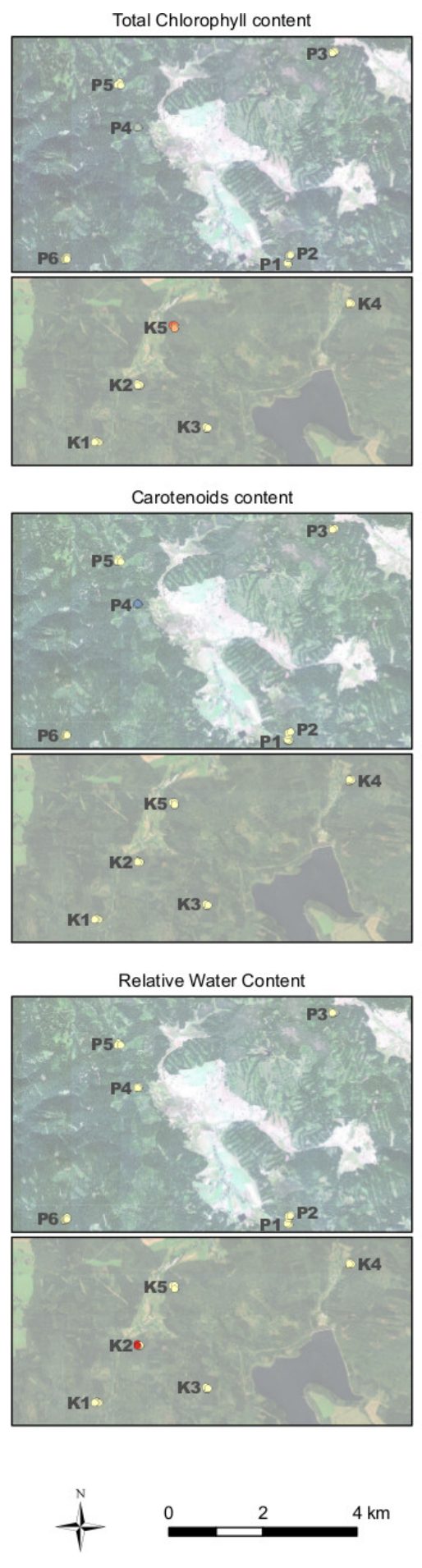

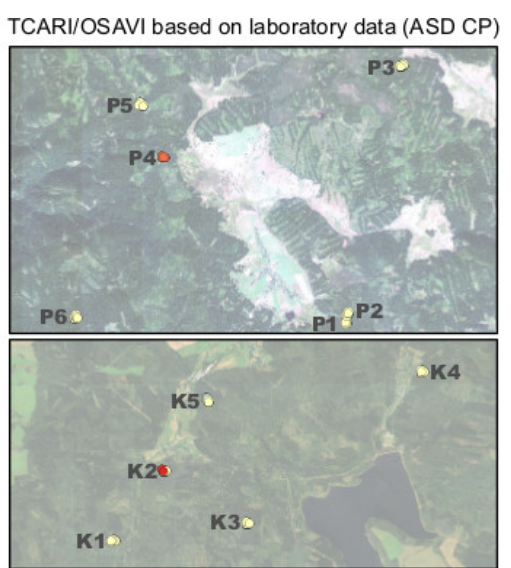

CRI700 based on laboratory data (ASD CP)

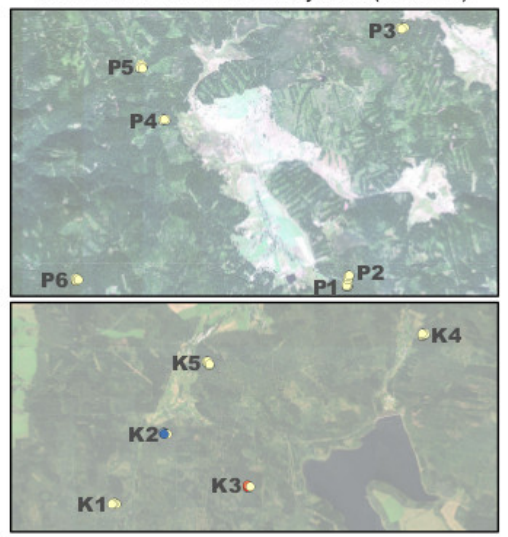

WI based on laboratory data (ASD CP)

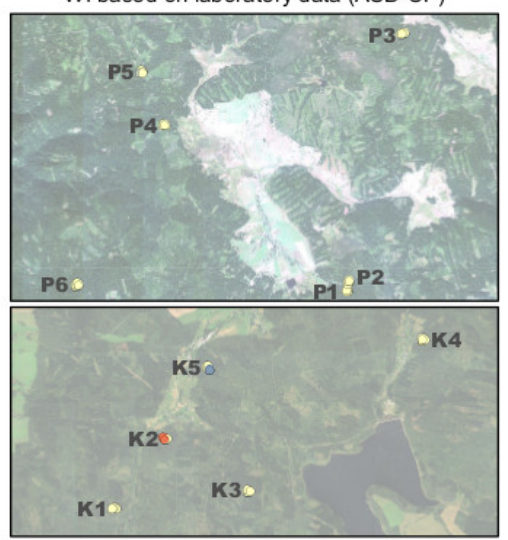

Hot Spot Analysis

- Cold Spot - $99 \%$ Confidence Cold Spot - $95 \%$ Confidence Cold Spot - 90\% Confidence

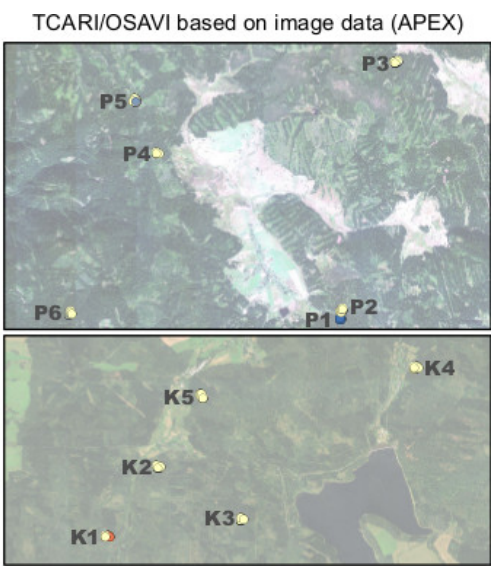

CRI700 based on image data (APEX)
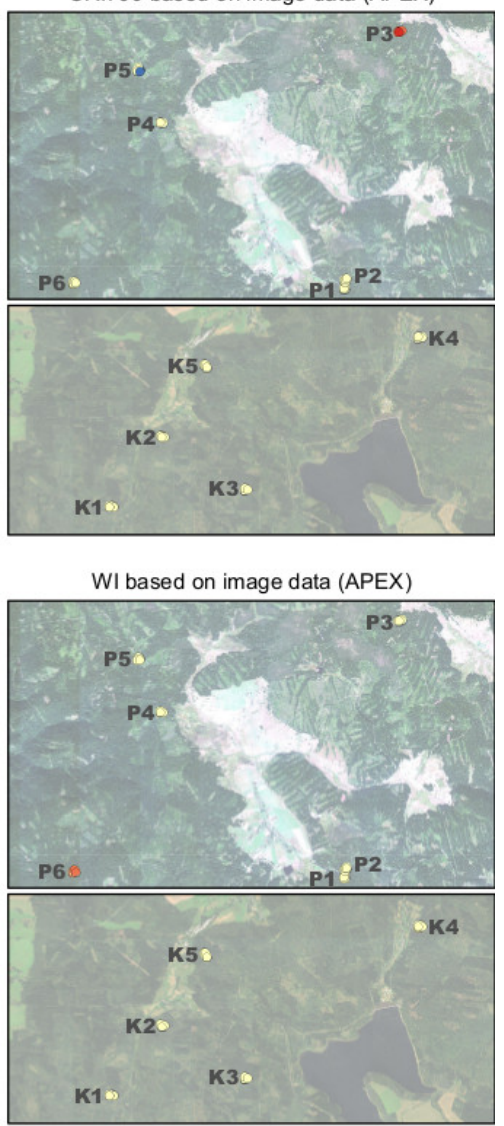

$\begin{array}{lll} & -\quad \text { Hot Spot - 90\% Confidence } \\ \text { Not Significant } & -\quad \text { Hot Spot - 95\% Confidence } \\ & -\quad \text { Hot Spot - 99\% Confidence }\end{array}$ 